\title{
Fundamentals of Liquid Crystal and Liquid Crystal Optics
}

\author{
Chang-Jae $\mathrm{Yu}^{1}$ and Sin-Doo $\mathrm{Lee}^{2 \dagger}$ \\ ${ }^{1}$ Department of Electronic Engineering, Hanyang University, Seoul 133-791, Korea \\ ${ }^{2}$ Department of Electrical and Computer Engineering, Seoul National University, Seoul 151-600, Korea
}

(Received July 25, 2013; Revised manuscript August 8, 2013; Accepted August 8 2013)

\begin{abstract}
The liquid crystal(LC) display is the most promising technology of the flat panel displays covering all applications from small mobile to large television applications. To understand the operating principles and improve the performances of the various LC displays, one should grasp the anisotropic nature of the LC and the propagation of light in the anisotropic media. Basic formulas governing the distribution of the LC molecules, directly related to the electro-optic effects of the LC devices, are described in view of the macroscopic interaction. Based on the matrix representation, the polarization analysis for the LC devices is also presented.
\end{abstract}

Keywords: Liquid crystals, Electro-optical devices, Liquid-crystal devices

OCIS codes: (160.3710) Liquid crystals; (230.2090), Electro-optical devices; (230.3720) Liquid-crystal devices

\author{
액정의 비등방 물성 및 광학 특성 \\ 유창재 $^{1} \cdot$ 이신두 $^{2 \dagger}$ \\ ${ }^{1}$ 한양대학교 융합전자공학부 \\ (ㄱ) 133-791 서울시 성동구 행당동 \\ ${ }^{2}$ 서울대학교 전기·정보공학부 \\ (우 151-600 서울시 관악구 신림동
}

(2013년 7월 25일 받음, 2013년 8월 8일 수정본 받음, 2013년 8월 8일 게재 확정)

액정 디스플레이는 소형에서 대형까지 모두 이용 가능한 가장 확실한 평판 디스플레이 구현 기술로 각광받고 있다. 액정 디스 플레이의 동작 원리뿐 만 아니라 성능 개선을 위해, 액정의 비등방성 및 비등방 매질에서 빛의 전파에 대한 이해가 필요하다. 액정 소자의 광학 특성에 영향을 주는 액정의 공간 분포에 관여하는 에너지를 통해 액정 디스플레이의 동작원리를 이해하고, 비등방 매질에서 빛의 편광 해석 방법을 통해 액정 디스플레이의 광학특성에 대해 기술한다.

Keywords: 액정, 전기광학 소자, 액정 디스플레이

OCIS codes: (160.3710) Liquid crystals; (230.2090), Electro-optical devices; (230.3720) Liquid-crystal devices

\section{I. 서 론}

현대사회에서 액정(liquid crystal: LC)은 휴대폰, 노트북 컴 퓨터, 텔레비전과 같은 정보디스플레이를 비롯하여 광통신 소자 등에도 널리 활용되고 있으며 더 나아가 액정의 유체성 과 여러 비등방적 성질로 인해 많은 분야에 응용되고 있다. 초기 액정에 대한 연구는 액체와는 다른 자연의 미묘한 상 (phase)에 대해 이해하고자 했다. 실제로, 초기에 액정이라는 단어는 액체(liquid)와 결정(crystal)의 중간 상(mesomorphic phase)을 의미하는 것으로 물질을 지칭하는 단어는 아니었
다. 하지만, 액정 상(liquid crystalline phase)이 모든 물질에 서 관찰되는 것이 아니라 특정한 형태의 분자에서만 관찰되 어, 현재는 통상적으로 액정 상을 갖는 물질이라는 의미로 "액정”이라는 용어를 쓰고 있다.

본 총설에서는 액정의 구조적 질서와 이에 따른 액정의 비 등방적 물성 및 광학 특성에 관한 기초적인 이론을 소개할 것이다. 액정 분자 구조의 비등방성으로 인해 액정 분자는 서로 이웃하는 분자와 나란하게 정렬하려는 특성을 보이게 되며 이러한 특정 방향으로의 정렬성으로 인해 거시적 물성 의 비등방성이 나타나게 된다. 일반적으로, 외부 전기장(자기

${ }^{\dagger}$ E-mail: sidlee@plaza.snu.ac.kr

Color versions of one or more of the figures in this paper are available online. 
장)과 비등방 상호작용을 통해 액정 분자의 정렬 방향을 제 어할 수 있으며, 액정의 정렬 방향이 빛의 편광을 조절한다. 전기광학 소자로서 액정 시편에서의 편광 변화 및 투과도를 $2 \times 2$ Jones 행렬법을 이용하여 해석적으로 구하고 의미를 설 명할 것이며, 뒤에 게재될 액정 디스플레이 소자의 동작원리 및 광학적 특성을 이해하는 기초를 제공할 것이다.

\section{II. 액정의 구조적 질서와 액정 상}

앞서 말한 것과 같이 액정은 겉으로 보이는 기계적 특성은 액체(liquid)와 같으나 구조적 특성은 결정(crystal)의 대칭성 을 부분적으로 갖는 중간 상(intermediate phase)이다. 일반적 으로, 분자 모양이 길쭉한 막대 모양이거나 납작한 원반 모 양인 경우에 액정 상이 관찰된다. 이러한 비등방적인 (anisotropic) 분자 모양은 분자간 상호작용력이 충분히 약한 액체 상태에서는 거시적으로 등방성(isotropy)을 보이지만, 온도가 낮아지고 분자간 거리가 가까워져 분자간 상호작용 력이 증가하면 개별 분자가 공간상에 차지하는 영역을 늘리 기 위해 비등방적인 액정 분자가 서로 나란하게 정렬하려는 경향을 보이게 된다. ${ }^{[1-3]}$ 이러한 액정 분자의 정렬성이 병진 및 회전 자유도를 갖고 있는 액체 또는 유체와는 달리 분자 의 회전 자유도를 제한하여 거시적으로 비등방성(anisotropy) 을 나타내게 된다. 즉, 보통의 액체에서는 정의할 수 없는 방 향 질서(orientational order)를 가지고 있지만 결정과 같이 완 전한 3차원의 위치 질서(positional order)를 가지고 있지는 않다. 위치 질서의 정도에 따라 다양한 액정 상이 존재한다. 액정은 분자 구조적으로 매우 큰 비등방성을 갖는 분자가 특 정 방향으로 정렬하여 매우 큰 전기적, 광학적 비등방성을 갖는다. 또한, 이러한 비등방성의 방향을 외부에서 인가하는 전기장 또는 자기장으로 쉽게 바꿀 수 있어서 전기광학 소자 로 활용할 수 있게 된다.

역사적으로, 액정의 발견은 1888년 오스트리아 식물학자 F. Reinitzer가 콜레스테롤에서 두 개의 녹는 점을 발견하고 이를 1889년 독일 물리학자 O. Lehmann이 광학적으로 분석 한 때로 거슬러 올라간다. ${ }^{[4]}$ 일반적으로 액정 상을 발현시키 는 인자의 종류에 따라 온도 전이형(thermotropic) 액정과 농 도 전이형(lyotropic) 액정으로 분류된다. 온도 전이형 액정에 서는 고체 또는 결정 상에서 온도를 높이면 액정 상이 발현 되고, 농도 전이형 액정에서는 분자의 농도가 증가하면 액정 상을 보이게 된다. 농도 전이형 액정은 생체물질에서 많이 발견되고 있어 생물학 분야에서 활발히 연구되고 있다. 온도 전이형 액정은 전기장 또는 자기장을 통해 액정 분자의 정렬 방향을 제어할 수 있어 물리학뿐 만 아니라 디스플레이 및 전기광학 소자와 관련된 응용분야에서 폭넓게 연구되고 있 다. ${ }^{[5]}$ 일반적으로, 막대 모양의 액정은 분자량이 비교적 작고 점성이 낮아 전기광학 소자로 활용되지만 원판 모양의 액정 은 분자량이 상대적으로 크고 점성이 높아 수동적인 광학소 자로 활용된다.

일반적으로, 막대 모양의 온도 전이형 액정은 위치 질서의
정도에 따라 네마틱(nematic: N) 상과 스멕틱(smectic: Sm) 상으로 구분되며, 분자의 chirality에 따라 카이랄(chiral) 액정 (상 이름 뒤에 *를 추가한다.)과 비카이랄(achiral) 액정으로 나뉜다. 카이랄 네마틱(N*) 액정은 콜레스테릭(cholesteric: $\mathrm{Ch}$ ) 액정으로 부르는데, 이는 처음 발견된 액정인 콜레스테 롤이 카이랄 네마틱 액정이었기 때문이다. 네마틱 상은 단지 방향 질서 만을 가지고 있는 액정 상이며 스멕틱 상은 방향 질서와 함께 1 차원 또는 2 차원의 위치 질서를 가지고 있는 상이다. 일반적으로 액정 분자의 공간 분포를 기술하기 위해 액정 분자의 평균 정렬 방향을 나타내는 단위벡터(n)인 방향 자(통상적으로 분자의 장축 방향)를 도입하며 극각(polar angle) $\theta$ 과 방위각(azimuthal angle) $\phi$ 로 기술된다. 분자의 chirality는 분자를 구성하는 탄소 분자의 네 개의 공유결합 에 각기 다른 원자 또는 분자가 결합되어 있는 경우에 거울 상을 이루는 두 가지 분자 구조의 이성질체가 가능한데, 이 가운데 하나의 구조만 존재하여 거울 대칭성이 깨지는 것을 나타내는 말이다. 두 이성질체는 같은 화학식을 갖지만 광학 적으로 빛의 편광 회전방향이 서로 반대로 나타난다. 또한, 액정 분자의 정렬에서도 이웃한 분자와 나란하게 정렬하는 것이 아니라 특정한 방향으로 비틀려 정렬하는 특성을 갖게 된다. 예를 들어, 비카이랄 네마틱에서 이웃한 액정 분자가 나란하게 정렬하려고 하는 것에 반해, 카이랄 네마틱에서는 비틀린 구조로 정렬하려고 하고 비틀린 구조가 반복되는 거 리를 피치라고 한다.(그림 1) 수평 정렬된 카이랄 네마틱 상 은 비틀린 방향과 피치가 동일한 입사 빛을 선택적으로 반사 시키며 나머지는 투과시키는 특성이 있다. ${ }^{[1]}$ 이러한 카이랄 네마틱 상을 이용하면, 편광판과 color filter 없이 반사형 디 스플레이를 제작할 수 있지만, 일반적으로 온도에 따라 피치 가 변하고, 가시광 전영역에 걸친 색 구현을 위해서는 복잡 한 구조와 공정이 필요하다. ${ }^{[6]}$

층 구조의 1 차원의 위치 질서를 갖고 있는 스멕틱 액정은 방향자와 위치 질서의 방향과 이루는 각도에 따라 스멕틱 $\mathrm{A}(\mathrm{Sm} \mathrm{A})$ 상과 스멕틱 $\mathrm{C}(\mathrm{Sm} \mathrm{C})$ 상으로 나뉜다. $\mathrm{Sm}$ A상은 위 치 질서의 방향이 액정 방향자와 나란하게 정렬된 상태(즉,

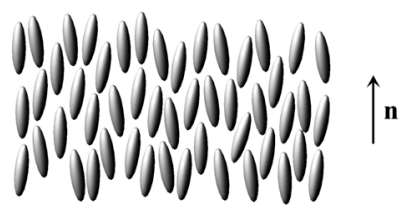

(a)

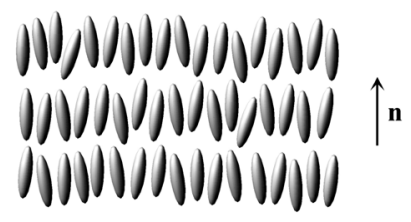

(c)

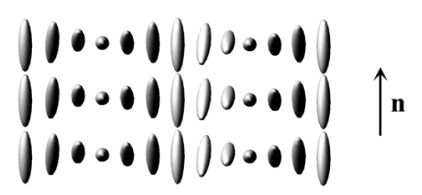

(b)

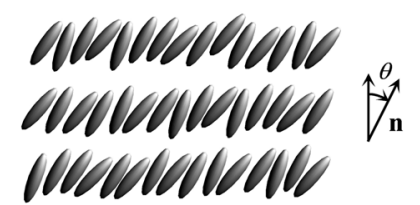

(d)
FIG. 1. Liquid crystalline phases; (a) nematic phase, (b) chiral nematic phase, (c) smectic A phase, and (d) smectic C phase. 


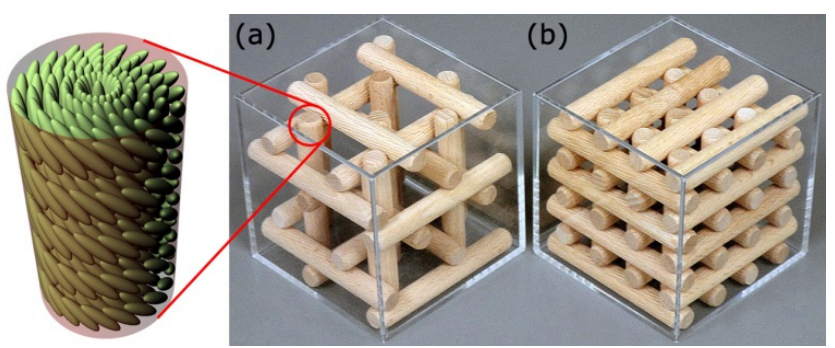

FIG. 2. Schematic diagram of the LC molecules in the blue phases: (a) the face-centered cubic structure of the BP I phase and the (b) simple cubic structure of the BP II phase.

액정 층과 액정의 방향자가 수직)를 나타내고, $\mathrm{Sm}$ C상은 위 치 질서의 방향이 액정의 방향자와 일정한 각도로 기울어진 상태를 나타낸다.(그림 1) 카이랄 스멕틱 $\mathrm{C}\left(\mathrm{Sm} \mathrm{C} \mathrm{C}^{*}\right.$ 상의 경 우, chirality 때문에 거울 대칭성이 깨져 개별 분자의 쌍극자 가 상쇄되지 않으며 나선(helix) 구조를 이루고 거시적으로 자발 분극이 유도된다. 특히, 자발 분극을 갖는 액정 상인 $\mathrm{Sm} \mathrm{C}$ *상을 강유전성 액정(ferroelectric liquid crystal: FLC) 라고 부른다. 그림 1 은 대표적인 액정 상의 분자 정렬 방향 을 개념적으로 나타낸 것이다.

피치가 수 백 $\mathrm{nm}$ 이하로 짧은 카이랄 네마틱 상을 갖는 액 정에서 액체와 카이랄 네마틱 상사이의 좁은 온도 구간에서 액정 분자는 그림 2 와 같이 2 차원 비틀린 구조의 원통형 액 정 배열을 갖게 되고 이러한 원통들이 3차원 공간에 교차한 형태를 갖게 된다. 이러한 액정 상은 현미경 상에서 일반적 으로 파란색을 띠고 있어 블루상(blue phase; BP)이라 한다. ${ }^{[1]}$ 일반적으로, 블루상은 가시광 영역에서 등방성을 보이며, 전 기장을 인가하면 Kerr 효과로 인해 비등방성이 유도되면 네 마틱 액정에 비해 빠른 응답속도를 얻을 수 있다. ${ }^{[7]}$ 원통형 액정 배열이 교차하는 부분은 액정 방향자의 변형이 공간적 으로 급격하게 일어나 특이점을 형성하게 된다. 이러한 특이 점을 연결하면 면심 입방(face-centered cubic) 구조(BP I 상) 또는 단순 입방(simple cubic) 구조(BP II 상)를 형성하게 된 다. 일반적으로 블루상은 액체와 카이랄 네마틱 상의 중간의 매우 좁은 온도 구간에서 관찰되지만, 광반응성 단분자를 블 루상 액정에 혼합하여 고분자화시키면, 특이점을 중심으로 고분자 사슬구조가 형성되어 블루상이 관찰되는 온도를 수 십도 수준으로 확대시킬 수 있다. ${ }^{[8]}$ 최근에, 고분자 안정화 블루상의 3 차원 자기 정렬 특성을 이용하여 전기장에 의한 가변 광자결정(photonic crystal)을 제작하는 방법과 이를 이 용한 광대역 레이저 기술이 제안되었다. ${ }^{[9,}{ }^{10]}$

\section{III. 액정의 비등방 물성}

현재, 디스플레이를 포함하여 대부분의 전기광학 소자로 사용되는 액정은 네마틱 액정이다. 네마틱 액정은 다양한 액 정 상 중에서 가장 단순하고 낮은 수준의 질서를 갖고 있어 대면적, 균일한 소자 제작이 용이하고 동역학적 성능이 우수

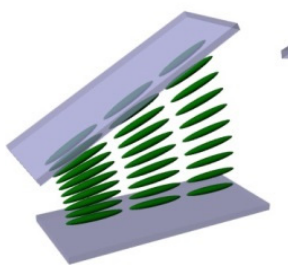

(a)

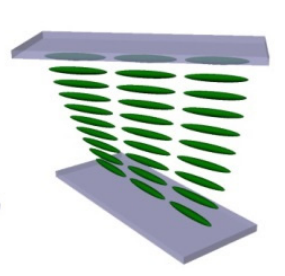

(b)

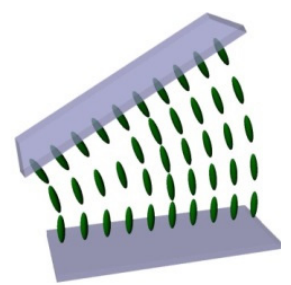

(c)
FIG. 3. Three types of deformations in the liquid crystal: (a) splay, (b) twist, and (c) bend deformations.

하다. 또한, 분자간 상호작용이 비교적 단순하고 이론적인 해석이 충분히 이루어져 있다. 일반적으로, 액정의 변형은 외부에서 인가되는 전기장(또는 자기장)과 액정과 경계를 이 루는 표면에 의해 유도되며 액정 분자간 상호작용이 이러한 변형을 억제하면서 평형상태(equilibrium)에 이른다. 실제로, 유체의 특성을 보이는 액정을 전기광학 소자로 제작하기 위 해서는 제한된 공간에 가둬야 하므로 액정과 특정한 표면 사 이의 상호작용이 액정의 변형에 영향을 주게 된다. 그러므로 액정 방향자(분자 장축의 평균방향)의 공간적인 분포는 액정 분자 사이의 상호작용을 나타내는 탄성 변형 에너지, 외부에 서 인가되는 전기장(자기장)과 액정의 전기적(자기적) 상호 작용 에너지, 그리고 가두는 공간을 형성하는 계면에서 액정 의 표면 고정 에너지(surface anchoring energy)에 의해 결정 되고, 세 가지 에너지의 합이 최소가 되는 액정 분포에서 평 형상태가 되며 변분법(calculus of variation)을 통해 구할 수 있다.

액정의 거시적인 변형은 탄성 연속체 이론(elastic continuum theory)을 바탕으로 액정의 공간적 변형을 구성 분자들의 배 열 상태로서 퍼짐(splay), 비틀림(twist), 휨(bend)의 세가지 독립적 성분으로 나누어 표현할 수 있다. ${ }^{[1]}$ 이는 용수철의 변 형에 따른 변형 에너지와 비슷하다. 액정의 탄성 변형 에너 지(elastic distortion energy)는 나란하게 정렬된 액정 분자가 그림 3에서 보여진 액정 분자의 공간적 분포와 같이 변형되 었을 때 저장된 에너지로 원래 나란한 상태로 복원하려는 힘 의 근원이 된다. 식 (1)은 방향자(n)의 공간 분포에 대해 단 위 부피당 액정의 변형 에너지 $\left(f_{d}\right)$ 를 나타내고, $K_{1}, K_{2}, K_{3}$ 는 각각 액정의 퍼짐, 비틀림, 휨 변형 상수로 정의되며 용수철 상수와 같은 역할을 한다.

$$
f_{d}=\frac{1}{2}\left[K_{1}(\nabla \cdot \mathbf{n})^{2}+K_{2}(\mathbf{n} \cdot \nabla \times \mathbf{n})^{2}+K_{3}(\mathbf{n} \times \nabla \times \mathbf{n})^{2}\right]
$$

탄성 계수는 일반적으로 $10^{-11} \mathrm{~N}$ 수준으로 대부분의 막대형 태의 분자로 구성된 액정의 경우 $K_{3}>K_{1}>K_{2}$ 의 대소 관계 를 보인다.

액정과 표면 사이의 상호작용을 기술하는 표면 고정에너지 는 표면에서 특정한 방향으로 액정 분자를 정렬시키고자 하 는 에너지이다. 애초에 정렬시키고자 했던 방향 $\left(\theta_{0}, \phi_{0}\right)$ 에 대 
해 실제로 표면에서 액정 분자가 정렬된 방향 $(\theta, \phi)$ 과의 차 이에 의해 결정된다. 일반적으로 다음과 같은 Rapini-Papoular 형태로 기술된다. ${ }^{[1]}$

$$
f_{s}=\frac{1}{2} W_{p} \sin ^{2}\left(\theta-\theta_{0}\right)+\frac{1}{2} W_{a} \sin ^{2}\left(\phi-\phi_{0}\right)
$$

여기서, $W_{p}$ 와 $W_{a}$ 는 각각 극각 고정 에너지(polar anchoring energy)와 방위각 고정 에너지(azimuthal anchoring energy)를 나타낸다.

전기장과의 상호작용은 액정을 전기광학 소자로 응용하는 데 있어서 가장 중요한 에너지이다. 앞서 언급한 것과 같이 가장 단순한 액정 상인 네마틱 상에서 액정은 방향자로 정의 된 방향으로 나란하게 정렬되어 있어 거시적으로 비등방성 을 띠게 된다. 유전체인 네마틱 액정은 외부 전기장에 의해 유도 분극이 나타나게 되는데, 액정의 비등방성으로 인해 유 도되는 분극은 인가된 전기장의 방향에 따라 서로 다르게 된 다. 이를 유전 이방성(dielectric anisotropy)이라고 하고 결정 에서 방향에 따라 서로 다른 격자 진동(lattice vibration)을 갖는 물질에서 관찰되는 현상과 동일하다. 네마틱 액정의 경 우, 방향자에 나란한 방향(액정의 장축 방향)과 수직한 방향 (액정의 단축 방향)이 서로 다른 유전상수 $\varepsilon_{\|}$과 $\varepsilon_{\perp}$ 를 갖는다. 실제로 수직한 방향은 평면으로 두 방향 성분이 존재하지만 네마틱 액정의 경우 두 방향은 같은 유전상수를 갖는다. 이 러한 비등방적인 액정에 전기장 $\mathbf{E}$ 를 인가하면, 유도되는 전 기변위 $\mathbf{D}$ 는 전기장을 액정의 장축 방향과 단축 방향으로 성 분분해를 하고 해당하는 유전상수를 곱하여 다음과 같이 표 현할 수 있다.

$$
\mathbf{D}=\varepsilon_{\perp} \mathbf{E}+\left(\varepsilon_{\|}-\varepsilon_{\perp}\right)(\mathbf{n} \cdot \mathbf{E}) \mathbf{n}
$$

여기서, $\varepsilon_{\|}-\varepsilon_{\perp}=\Delta \varepsilon$ 으로 액정의 유전 이방성을 나타내며 물질에 따라 크기와 부호가 다르다. 유전체에서 전기 에너지 밀도는 전기장과 전기변위의 내적의 절반으로 표현되어,

$$
f_{e}=-\frac{1}{2} \mathbf{D} \cdot \mathbf{E}=-\frac{1}{2} \varepsilon_{\perp} E^{2}-\frac{1}{2}\left(\varepsilon_{\|}-\varepsilon_{\perp}\right)(\mathbf{n} \cdot \mathbf{E})^{2}
$$

위 식에서 첫 번째 항은 전기장의 세기의 제곱에 비례하는 값이지만, 액정의 방향자(n)과는 무관한 항이다. 반면에, 두 번째 항은 전기장과 액정의 방향자에 의해 변하는 항이므로 액정에 전기장을 인가했을 때 액정의 방향자 분포의 변화를 유도하게 된다. 여기서, 주목할 점은 네마틱 액정의 전기 에 너지 밀도는 전기장의 극성에 무관하다는 점이다. 액정의 방 향자와 무관한 전기장의 제곱에 비례하는 항은 일반적으로 액정의 총 변형 에너지를 계산할 때는 무시한다. 특히, 식 (4)으로부터 전기장을 인가했을 때 액정 장축의 정렬 방향을
예측할 수 있다. 예를 들어, 양의 유전 이방성 $(\Delta \varepsilon>0)$ 을 갖 는 액정의 경우 전기장을 인가하면, 전기장에 의한 에너지를 최소화 하기 위해 액정의 방향자 $\mathbf{n}$ 은 전기장 $\mathbf{E}$ 의 방향과 나 란하게 정렬하려고 한다. 반면, 음의 유전 이방성 $(\Delta \varepsilon<0)$ 을 갖는 액정에서는 액정의 방향자가 전기장과 수직한 방향으 로 정렬하려고 한다. 일반적으로, 전기 에너지 밀도가 커질 수록 액정 방향자의 변형 속도는 빨라지므로 빠른 응답속도 를 요구하는 액정 전기광학 소자에는 큰 유전 이방성을 갖는 액정이 필요하다.

자발 분극(P)을 갖는 강유전성 액정은 유전 이방성에 의한 전기 에너지보다 자발 분극에 의한 전기 에너지(P-E)가 매 우 크므로 주로 자발 분극 효과를 고려한다. 대부분의 강유 전성 액정은 네마틱 보다 전기장에 의한 분자의 응답속도가 빠르다. Sm C*상에서 자발 분극의 존재는 1975년 R. B. Meyer가 chirality에 의해 장축을 중심으로 한 회전력이 억제 되어 분자의 쌍극자가 상쇄되지 않아 대칭성이 깨짐을 이론 적으로 예측했다. ${ }^{[12]}$ 자발 분극의 방향은 액정의 장축 방향과 장축이 스멕틱 층으로부터 기울어진 방향에 모두 수직인 방 향으로 존재하며, 크기는 기울어진 각에 비례한다. 강유전성 액정에서 전기 에너지는 전기장에 선형 비례하므로 네마틱 액정과는 달리 전기장의 극성에 따라 액정의 방향은 서로 다 르게 정렬하게 된다. 하지만, 엄밀하게 말해서, 비록 자발 분 극이 부분적으로 존재하더라도 $\mathrm{Sm} \mathrm{C}$ *가 갖는 나선 구조 때 문에 주기에 대해 평균적으로는 거시적인 자발 분극이 사라 지게 된다. 따라서 외부에서 적절한 전기장을 인가하여 분자 쌍극자와 선형 결합을 통해 나선 구조가 풀리면서 자발 분극 이 나타나게 된다. 그림 4에 강유전성 액정의 방향자 및 자 발 분극의 분포를 나타냈다.

자발 분극이 존재하지 않는 네마틱의 경우에도 압전 효과 (piezoelectric effect)와 비슷하게 변형의 형태가 액정 분자의

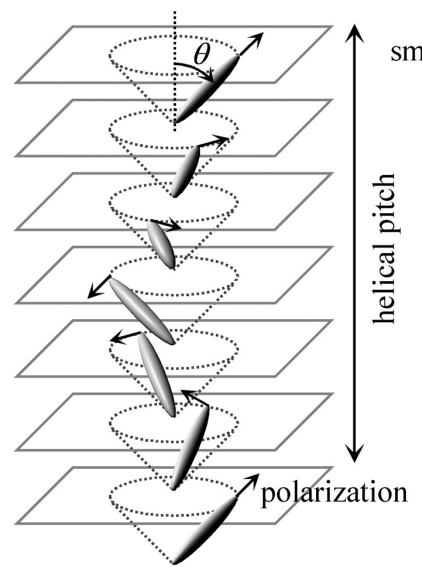

(a)

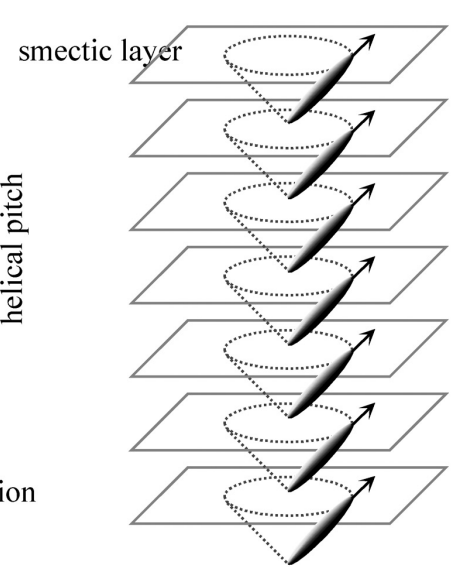

(b)
FIG. 4. Distributions of the LC director and the dipole moment in the ferroelectric liquid crystal (a) in the absence of an applied field (helical structure) and (b) in the presence of the applied field (unwound configuration). 

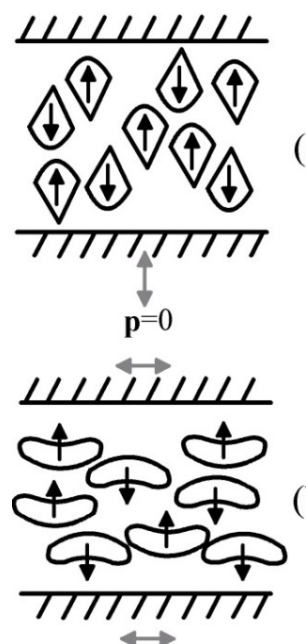

$\mathbf{p}=0$ (a)

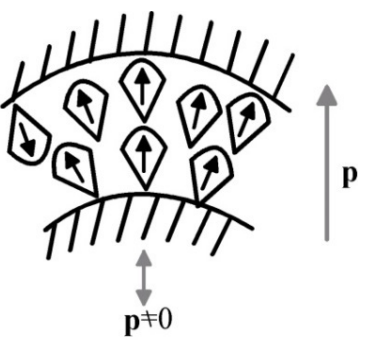

(b)

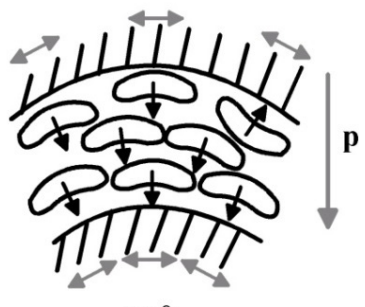

$\mathbf{p} \neq 0$

FIG. 5. (a) Splay flexoelectric effect induced by the splay deformation of the wedge-shaped molecules with a longitudinal dipole and (b) bend flexoelectric effect induced by the bend deformation of the banana-shaped molecules with a transverse dipole.

대칭성을 깨는 경우에는 유도 분극이 나타나서 전기장의 극 성에 따라 다른 전기 에너지가 유도된다. R. B. Meyer는 액 정 분자가 퍼짐 또는 휨 변형을 하는 경우, 변전 효과 (flexoelectric effect)에 의해 분극이 유도될 수 있음을 밝혔 다. ${ }^{[13]}$ 그림 5에 나타낸 것과 같이, 구조적 비대칭성을 갖는 분자에서 퍼짐 또는 휨 변형으로 인해 분자 배열의 대칭성이 깨져 거시적으로 분극이 유도된다. 유도되는 분극 $\left(\mathbf{P}_{d}\right)$ 은 다 음의 식으로 표현된다.

$$
\mathbf{P}_{d}=e_{1} \mathbf{n}(\nabla \cdot \mathbf{n})+e_{3}(\nabla \times \mathbf{n}) \times \mathbf{n}
$$

여기서, $e_{1}$ 과 $e_{3}$ 는 각각 퍼짐과 휨 변전 계수를 나타내고 단 위는 $\mathrm{C} / \mathrm{m}$ 이다. 최근에 네마틱 액정에서 고속 응답을 구현하 기 위해 변전 효과를 이용하는 방법이 연구되고 있다. ${ }^{[14]}$

평형상태에서 액정 분자의 공간 분포는 변분법을 통해 탄 성 변형 에너지, 전기적 상호작용 에너지, 그리고 표면 고정 에너지의 합을 최소화하여 구할 수 있다. 총 에너지 $\left(F_{T}\right)$ 는 방 향자 벡터와 방향자의 공간 미분의 함수로 기술되며, 실제 방향자는 $\theta$ 와 $\phi$ 로 표현되므로 결과적으로 $\theta$ 와 $\phi$ 그리고 각 각의 공간 미분으로 표현된다. 변분법에 따라, $\theta$ 와 $\phi$ 각각에 대해 Euler-Lagrange equation을 만족하는 해를 구할 수 있 다. ${ }^{[15]}$

$$
\begin{aligned}
& -\frac{\partial F_{T}}{\partial \theta}+\frac{d}{d x} \frac{\partial F_{T}}{\partial \theta_{x}}+\frac{d}{d y} \frac{\partial F_{T}}{\partial \theta_{y}}+\frac{d}{d z} \frac{\partial F_{T}}{\partial \theta_{z}}=0 \\
& -\frac{\partial F_{T}}{\partial \phi}+\frac{d}{d x} \frac{\partial F_{T}}{\partial \phi_{x}}+\frac{d}{d y} \frac{\partial F_{T}}{\partial \phi_{y}}+\frac{d}{d z} \frac{\partial F_{T}}{\partial \phi_{z}}=0
\end{aligned}
$$

여기서, $\theta_{i}(i=x, y, z)$ 와 $\phi_{i}$ 는 극각과 방위각의 $x, y, z$ 방향 으로의 편미분을 나타낸다. 일반적으로 위 편미분 방정식은 해석해(analytic solution)를 구할 수 없어서 수치해석을 통해, 위치에 따른 $\theta$ 와 $\phi$ 값을 구할 수 있다. 이렇게 구해진 액정 분자의 공간 분포는 액정의 광학적 특성을 계산하는 데 유용 하게 활용된다.

\section{IV. 액정의 광학적 특성}

액정의 광학 특성을 이해하기 위해서는 비등방 매질에서 편광된 빛의 전파에 대해서 먼저 이해해야 한다. 앞서 설명 한 것처럼 액정은 전기적으로 비등방성을 갖고 있으므로 전 자기파에 대해서도 비등방적인 광학 현상을 보이게 된다. 등 방성 유전 매질에서 빛은 편광 방향에 무관하게 굴절률에 의 해 매질 안에서의 빛의 속도가 변하게 된다. 일반적으로 굴 절률의 제곱은 상대 유전상수와 상대 자기상수의 곱으로 표 현된다. 액정을 포함한 대부분의 물질은 비자기 물질로 상대 자기상수를 1 로 간주할 수 있다. 그러므로 굴절률은 통상적 으로 상대 유전상수의 제곱근으로 표현할 수 있다. ${ }^{[16]}$ 등방성 매질에서 유전상수는 빛의 편광 방향 즉 전기장 방향에 무관 한 스칼라(scalar)로 표현되지만, 비등방성 유전 매질에서는 유전상수가 전기장의 방향에 따라 다른 값을 갖는 유전 텐서 (dielectric tensor) $\varepsilon$ 로 표현된다. 유전 텐서는 $3 \times 3$ 행렬로 표 현되며, 주축(principal axis) 방향으로 대각화(diagonalization) 하면 세 개의 주유전상수(principal dielectric constants)를 구 할 수 있다. 비등방 매질에 대해 Maxwell equations을 정리하 면, 다음과 같은 식을 유도할 수 있다.

$$
\nabla \times(\nabla \times \mathbf{E})=\nabla(\nabla \cdot \mathbf{E})-\nabla^{2} \mathbf{E}=-\mu_{0} \frac{\partial^{2} \mathbf{D}}{\partial t^{2}}=-\varepsilon_{0} \mu_{0} \varepsilon \frac{\partial^{2} \mathbf{E}}{\partial t^{2}}
$$

이제, $\varepsilon_{x}, \varepsilon_{y}, \varepsilon_{z}$ 으로 표현되는 주유전상수와 $\mathbf{k}=k_{x} \mathbf{x}+k_{y} \mathbf{y}+$ $k_{z} \mathbf{Z}=(2 \pi n / \lambda) \mathbf{s}$ 로 표현되는 파수 벡터(wave vector)를 이용하 여 식 (7)을 $x, y, z$ 성분으로 분해할 수 있다.

$$
\begin{aligned}
& \left(k_{0}^{2} \varepsilon_{x}-k_{y}^{2}-k_{z}^{2}\right) E_{x}+k_{x} k_{y} E_{y}+k_{x} k_{z} E_{z}=0 \\
& k_{y} k_{x} E_{x}+\left(k_{0}^{2} \varepsilon_{y}-k_{x}^{2}-k_{z}^{2}\right) E_{y}+k_{y} k_{z} E_{z}=0 \\
& k_{z} k_{x} E_{x}+k_{z} k_{y} E_{y}+\left(k_{0}^{2} \varepsilon_{z}-k_{x}^{2}-k_{y}^{2}\right) E_{z}=0
\end{aligned}
$$

이때, 벡터 $\mathbf{s}=s_{x} \mathbf{x}+s_{y} \mathbf{y}+s_{z} \mathbf{z}$ 는 빛의 진행 방향을 나타내는 단위 벡터이고, $n$ 은 $\mathbf{k}$ 방향으로 진행하는 빛의 굴절률이다. 이때, 상기해야 할 사항은 주유전상수 $\varepsilon_{x}, \varepsilon_{y}, \varepsilon_{z}$ 가 해당 방향 의 굴절률 $n_{x}^{2}, n_{y}{ }^{2}, n_{z}^{2}$ 이라는 것이다. 전기장에 대해 자명하 지 않은 해(non-trivial solution)가 존재하기 위해서는 식 (8) 을 전기장에 대한 행렬 방정식으로 표현했을 때 행렬식 (determinant)가 0이 되어야 한다. 이로부터 굴절률 $n$ 이 $n_{x}$, $n_{y}, n_{z}$ 가 아닐 때 가질 수 있는 해는 Fresnel equation으로 표 현할 수 있다. ${ }^{[15]}$ 


$$
\frac{s_{x}^{2}}{n^{2}-n_{x}^{2}}+\frac{s_{y}^{2}}{n^{2}-n_{y}^{2}}+\frac{s_{z}^{2}}{n^{2}-n_{z}^{2}}=\frac{1}{n^{2}}
$$

위 식에서 두 개의 양의 값을 갖는 굴절률 $n$ 을 구할 수 있다. 두 굴절률은 $\mathbf{k}$ 방향으로 진행하는 빛에 수직한 평면 상의 두 주축 방향 즉 두 편광 방향에 대한 굴절률을 나타낸다. 두 주축 방향을 구하는 것은 고유벡터(eigenvector) 문제를 푸는 것으로 식 (9)의 두 해에 대해 다음과 같은 고유벡터를 구할 수 있다. ${ }^{[15]}$

$$
\mathbf{E}=\left(\begin{array}{c}
s_{x} /\left(n_{x}^{2}-n^{2}\right) \\
s_{y} /\left(n_{y}^{2}-n^{2}\right) \\
s_{z} /\left(n_{z}^{2}-n^{2}\right)
\end{array}\right)
$$

고유벡터 방향으로 편광된 빛은 매질을 통과하면서 편광상 태는 변하지 않으며, 단지 빛의 속도만 해당 굴절률에 따라 변하게 된다. 그러므로, 비등방 매질에 복잡한 편광상태의 빛이 입사하는 경우, 고유벡터와 해당하는 굴절률(고유값 eigenvalue)를 구하고 임의의 편광을 고유벡터 방향으로 성 분 분해하면 빛의 진행을 쉽게 분석할 수 있다.

고유벡터와 고유값을 직관적으로 이해하기 위해 그림 6 와 같 은 좌표계를 생각해보자. ${ }^{[16]}$ 대각화된 주축을 각기 $x, y, z$ 으로 하고 대응되는 비등방 매질의 굴절률을 $n_{x}, n_{y}, n_{z}$ 이라고 하면, 임의의 방향에 대한 비등방 매질의 굴절률 타원체 방정식은

$$
\frac{x^{2}}{n_{x}^{2}}+\frac{y^{2}}{n_{y}^{2}}+\frac{z^{2}}{n_{z}^{2}}=1
$$

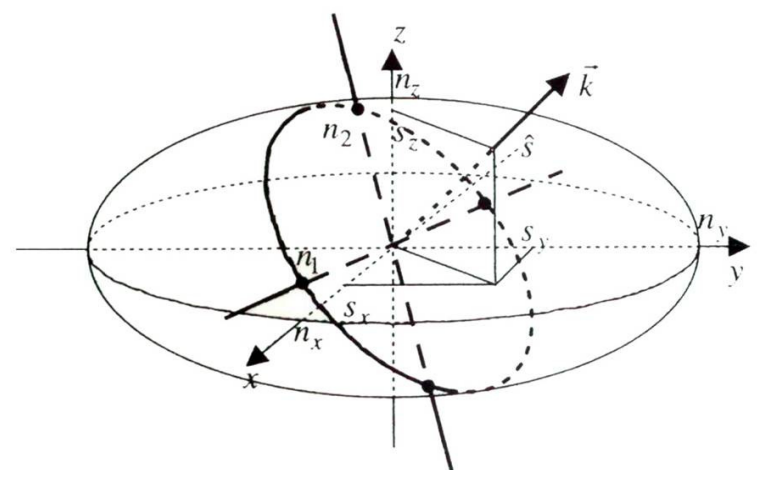

FIG. 6. Two eigenvalues (refractive indices) and two corresponding eigenvectors (polarizations) for the propagating light along the s-direction in an ellipsoid of the refractive indices. The intersectional ellipse between the ellipsoid and the plane perpendicular to the light-propagating direction represents the allowable refractive indices. The longest and the shortest axes directly correspond to the eigenvectors. $^{[16]}$
를 만족하고, $\mathbf{s}$ 방향으로 입사하는 빛에 수직한 평면의 방정 식은

$$
0=\mathbf{s} \cdot(x \mathbf{x}+y \mathbf{y}+z \mathbf{z})=s_{x} x+s_{y} y+s_{z} z
$$

를 만족한다. 식 (11)과 식 (12)를 동시에 만족하는 해는 타 원의 방정식이 되며, 타원의 장축과 단축 방향이 $\mathbf{s}$ 방향으로 입사된 빛의 고유벡터(편광) 방향이 되고 장축과 단축 길이 의 절반이 각각 해당하는 고유벡터의 고유값 즉 굴절률이 된다.

식 (8)에서 $\mathbf{k}$ 벡터의 한 성분이 없는 특별한 경우에 대해 해 를 구하면 그림 7과 같이 표현할 수 있다. 세가지 경우에 대 해, 각각 원의 방정식과 타원의 방정식이 구해지며, 입사 방 향 $\mathbf{k}$ 에 대해 양의 굴절률이 각각 하나씩 구해진다. 두 굴절 률이 앞서 논의한 고유값이다. 일반적으로 $n_{x}, n_{y}, n_{z}$ 가 모두 다른 경우에는 원과 타원의 방정식에서 구해지는 굴절률이 같아지는 광축(optic axis)이 두 방향에서 나타난다.(엄밀하게 는 4 방향에서 원과 타원의 방정식이 해가 일치하지만, 반사 빛을 제외한 입사 빛만 고려하면 2방향만 존재하게 된다. 입 사 빛과 반사 빛은 서로 반대 방향이다) 두 개의 광축을 갖 는 매질, 즉 세 방향의 굴절률이 모두 다른 매질을 이축성 (biaxial) 매질이라고 한다. 세 방향 중 두 방향의 굴절률이

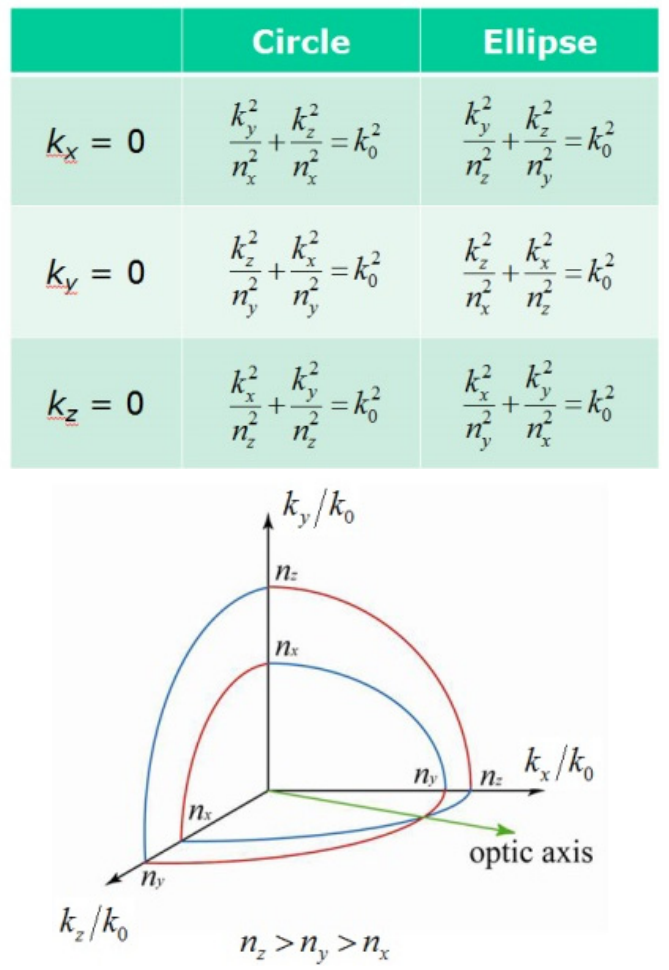

FIG. 7. The refractive indices of a biaxial medium in the $k$-space. For a given $\mathbf{k}$ vector lying on a coordinate plane, two allowable and positive refractive indices are determined from two equations of a circle (red curve) and an ellipse (blue curve) on the coordinate plane. The $\mathbf{k}$-direction with the same refractive indices from the two equations is called an optic axis. 
같고 $\left(n_{0}\right)$ 나머지와는 다른 $\left(n_{e}\right)$ 매질은 광축이 하나만 나타나 기 때문에 단축성(uniaxial) 매질이라고 한다. 단축성 매질은 다른 굴절률 하나의 크기가 같은 두 굴절률보다 큰 경우 $\left(n_{e}\right.$ $>n_{o}$ )를 양의 단축성(positive uniaxial)이라 하고 반대로 $n_{e}<$ $n_{o}$ 를 음의 단축성(negative uniaxial)이라고 한다.

일반적으로 네마틱 액정은 단축성 매질로 간주할 수 있다. 예를 들어, 단축성 매질에 $\mathbf{s}$ 방향으로 빛이 통과하는 경우에 대해 고유벡터와 해당 굴절률을 계산해 보자. 먼저, 단축성 매질에서 주축 방향의 굴절률 $n_{x}=n_{y}=n_{o}, n_{z}=n_{e}$ 로 정의하 고 빛의 입사 방향 $\mathbf{s}=\sin \theta \cos \psi \mathbf{x}+\sin \theta \sin \psi \mathbf{y}+\cos \theta \mathbf{z}$ 로 정의하자. 식 (9)로부터 두 개의 굴절률 $n_{1}, n_{2}$ 를 구할 수 있다.

$$
\begin{aligned}
& n_{1}=n_{o} \\
& n_{2}=\frac{n_{o} n_{e}}{\sqrt{n_{e}^{2} \cos ^{2} \theta+n_{o}^{2} \sin ^{2} \theta}}
\end{aligned}
$$

여기서, 식 (13a)는 빛의 입사 방향에 무관하게 항상 일정한 값을 갖지만, 식 $(13 \mathrm{~b})$ 는 빛의 입사각도에 따라 변한다. 두 굴절률에 대한 고유벡터는 빛의 횡파 특성과 식 (10)을 이용 해서 각각 구할 수 있다.

$$
\begin{aligned}
& \mathbf{E}_{1}=(\sin \psi-\cos \psi 0)^{T} \\
& \mathbf{E}_{2}=\left(n_{e}^{2} \cos \theta \cos \psi n_{e}^{2} \cos \theta \sin \psi-n_{o}^{2} \sin \theta\right)^{T}
\end{aligned}
$$

이때, $n_{1}$ 에 대한 고유벡터를 보통파(ordinary wave)라고 하고 $n_{2}$ 에 대한 고유벡터를 특이파(extraordinary wave)라고 한다. 여기서 주목할 사항은, 보통파 $\mathbf{E}_{1}$ 은 입사 빛 $\mathbf{s}$ 와 직교 $\left(\mathbf{E}_{1} \cdot \mathbf{s}=\right.$ $0)$ 하지만, 특이파 $\mathbf{E}_{2}$ 와 $\mathbf{s}$ 는 직교하지 않는다. $\left(\mathbf{E}_{2} \cdot \mathbf{s} \neq 0\right) \mathbf{E}_{2}$ 는 $\mathbf{s}$ 와 $z$ 축이 이루는 평면 상에 존재한다. 그림 8 에서 입사 빛과 고유벡터의 관계를 나타냈다.

이제까지 단축성 매질에서 빛의 편광에 따른 굴절률의 변 화에 대해 논의했다. 앞서 2장에서 논의했듯이, 비등방적 액

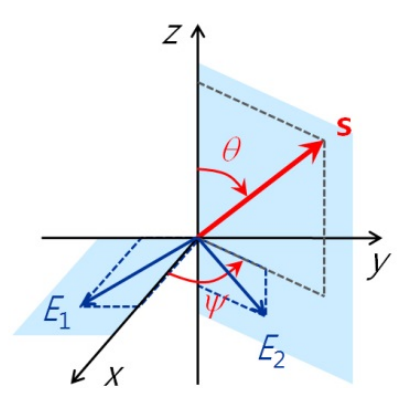

FIG. 8. The relationship between the light-propagating direction (s) and the two eigenvectors $\left(\mathbf{E}_{1}\right.$ and $\left.\mathbf{E}_{2}\right)$
정 방향자는 탄성 에너지, 전기적 에너지 및 표면 고정 에너 지에 의해 공간 상에 왜곡된 분포를 갖게 된다. 총 에너지 최소화를 통해 공간 상의 방향자 분포를 구하게 되면, 각 방 향자는 개별 단축성 매질로 간주할 수 있다. 결과적으로 서 로 다른 단축성 매질이 연속적으로 쌓여 있는 구조가 거시적 인 액정 매질이 되는 것이다. ${ }^{[15]}$ 이렇게 서로 다른 단축성 매 질이 연속적으로 쌓여 있는 매질의 광학 현상을 쉽게 이해하 는 방법으로 $2 \times 2$ Jones 행렬법이 있다. ${ }^{[15]}$ Jones 행렬법에서 빛의 진행 방향은 $z$ 축으로 정의하고, 빛의 편광을 기술하는 Jones 벡터는 전기장의 $x, y$ 축 성분 중에서 복소수 진폭을 벡 터의 $x, y$ 성분으로 정의한다. 편의상 입사 편광의 Jones 벡 터는 단위벡터로 표현한다. 편광 상태를 바꾸는 선형 광학소 자는 $2 \times 2$ Jones 행렬로 표현할 수 있으며 선형 광학소자를 통과한 빛의 편광 상태는 입사 편광을 표현하는 Jones 벡터 와 광학소자를 표현하는 행렬의 곱셈을 통해 쉽게 다시 Jones 벡터로 표현된다. 서로 다른 단축성 매질이 연속적으 로 쌓여 있는 액정 매질 전체를 통과한 빛의 편광상태는 각 단축성 매질에 대응되는 $2 \times 2$ Jones 행렬을 구해서 순차적으 로 행렬 곱을 연산하면 얻어진다.

이제, 액정의 광학 특성 분석에 필요한 편광자와 단축성 매질을 표현하는 $2 \times 2$ Jones 행렬에 대해 논의하고자 한다. 먼저, 빛의 투과 축이 $x$-축과 나란한 편광판의 경우, 모든 입 사 빛 중에서 $x$-방향 성분은 그대로 통과시키고 수직한 성분 즉 $\mathrm{y}$-방향 성분은 모두 흡수하여, 최종적으로 편광자를 통과 한 빛의 편광은 $x$-방향 성분만 남게 된다. 그러므로, 투과 축 이 $x$-축과 나란한 편광판을 표현하는 $2 \times 2$ Jones 행렬 $\mathbf{M}_{P x}$ 은 다음과 같이 표현할 수 있다.

$$
\mathbf{M}_{P x}=\left(\begin{array}{ll}
1 & 0 \\
0 & 0
\end{array}\right)
$$

마찬가지로, 투과 축이 $y$-축과 나란한 편광판의 $2 \times 2$ Jones 행렬도 같은 방법으로 구할 수 있다. 일반적으로 편광자의 방향이 $x$-축과 임의의 각도 $\phi$ 를 이루고 있을 때 $2 \times 2$ Jones 행렬 $\mathbf{M}_{P}(\phi)$ 을 구하기 위해서는 좌표계 변환을 이용하면 된 다. 먼저, $x y$-좌표계에서 편광자의 투과 축과 나란한 방향이 새로운 $x^{\prime} y^{\prime}$-좌표계의 $x^{\prime}$-축이 되도록 좌표계를 $\phi$ 만큼 회전 변환 행렬 $\mathbf{R}(\phi)$ 을 이용하여 변환시키고, 새로운 $x^{\prime} y^{\prime}$-좌표계 에서 투과 축이 $x^{\prime}$-축 나란한 편광자의 $2 \times 2$ Jones 행렬인 $\mathbf{M}_{P x}$ 를 적용한 후에, 최종 결과를 원래 $x y$-좌표계로 되돌리기 위해 좌표계를 $-\phi$ 만큼 회전 변환 $\mathbf{R}(-\phi)$ 시키면 된다.

$$
\begin{aligned}
\mathbf{M}_{P}(\phi) & =\mathbf{R}(-\phi) \mathbf{M}_{P x} \mathbf{R}(\phi) \\
& =\left(\begin{array}{cc}
\cos \phi & -\sin \phi \\
\sin \phi & \cos \phi
\end{array}\right)\left(\begin{array}{ll}
1 & 0 \\
0 & 0
\end{array}\right)\left(\begin{array}{cc}
\cos \phi & \sin \phi \\
-\sin \phi & \cos \phi
\end{array}\right)(16) \\
& =\left(\begin{array}{cc}
\cos ^{2} \phi & \cos \phi \sin \phi \\
\cos \phi \sin \phi & \sin ^{2} \phi
\end{array}\right) .
\end{aligned}
$$


단축성 매질은 두 고유벡터의 편광 방향에 대해 서로 다른 굴절률을 가지고 각각 편광성분은 서로 영향을 끼치지 않으 므로 매질을 통과하는 동안 독립적으로 위상 변화를 갖게 된 다. 그러므로, $2 \times 2$ Jones 행렬은 주대각 성분만 0 이 아닌 값 을 갖고 나머지 성분은 0 이 된다. 편의상 빛의 속도가 느린 편광 방향(slow axis)의 굴절률을 $n_{s}$ 로 정의하고 빠른 편광 방향(fast axis)의 굴절률을 $n_{f}$ 로 정의한다. Slow axis가 $x$-축 과 나란한 경우, 입사 빛의 $x$-성분은 매질의 두께 $d$ 를 통과하 는 동안, $\exp \left(-i 2 \pi n_{s} d / \lambda\right)$ 의 위상지연을 경험하게 된다. 마찬 가지로, fast axis는 $\exp (-i 2 \pi n f d / \lambda)$ 의 위상지연을 경험하게 된다. 이를 행렬 $\mathbf{W}(\Gamma)$ 로 표현하면 다음과 같다.

$$
\begin{aligned}
\mathbf{W}(\Gamma) & =\left(\begin{array}{cc}
\exp \left[-i \frac{2 \pi n_{s} d}{\lambda}\right] & 0 \\
0 & \exp \left[-i \frac{2 \pi n_{f} d}{\lambda}\right]
\end{array}\right) \\
& =\exp [-i \Phi]\left(\begin{array}{cc}
\exp \left[-i \frac{\Gamma}{2}\right] & 0 \\
0 & \exp \left[i \frac{\Gamma}{2}\right]
\end{array}\right)
\end{aligned}
$$

여기서, $\Gamma=2 \pi\left(n_{s}-n_{f}\right) d / \lambda=2 \pi \Delta n d / \lambda, \Phi=\pi\left(n_{s}+n_{f}\right) d / \lambda$ 를 나타낸다. 특히, $\Delta n=\left(n_{s}-n_{f}\right)$ 을 굴절률 이방성이라고 하 며 액정의 물질상수로 광학특성에 매우 중요한 역할을 한다. 편광된 빛이 식 (17)로 표현되는 단축성 매질을 통과하면, $x$ 방향 성분의 위상은 $y$-방향 성분의 위상보다 $\Gamma$ 만큼 지연되 어 위상 지연판(wave retarder)이라고 부른다.

편광자에서와 마찬가지로, 단축성 매질의 slow axis가 $x$-축 으로부터 $\phi$ 만큼 회전되어 있는 경우에는, 먼저 회전 변환 $\mathbf{R}$ $(\phi)$ 를 적용하여 $x$-축이 매질의 slow axis와 나란하도록 좌표 계 변환을 한 후에, 식 (17)을 적용하고, 다시 원래 $x$-축으로 되돌리기 위해 $\mathbf{R}(-\phi)$ 를 연산하면 최종적으로 위상 지연판을 표현하는 $2 \times 2$ Jones 행렬 $\mathbf{W}(\Gamma, \phi)$ 을 구할 수 있다.

$$
\mathbf{W}(\Gamma, \phi)=\mathbf{R}(-\phi) \mathbf{W}(\Gamma) \mathbf{R}(\phi)
$$

앞서 언급한 것처럼 연속적인 단축성 매질로 이루어진 액 정 전기광학 소자는 각 방향자 분포를 통해 식 (13)과 식 (14) 로부터 해당 영역의 단축성 매질의 고유벡터 방향과 해당 굴 절률을 구할 수 있다. 액정 방향자의 극각 $(\theta)$ 와 방위각 $(\phi)$ 을 그림 8 의 $\mathbf{s}$ 방향으로 정의하고 빛이 $z$-축으로 입사하는 경우 를 고려하면, 식 (17)의 $n_{s}$ 와 $n_{f}$ 는 식 (13)의 $n_{2}, n_{1}$ 에 각각 대 응된다. 또한, slow axis의 회전 각도는 액정 방향자의 방위 각 $\phi$ 와 같게 된다. 빛의 진행 방향으로 특정 $z_{i}$ 위치에 있는 두께 $\Delta z$ 인 액정 층의 방향자를 $\theta\left(z_{i}\right)$ 와 $\phi\left(z_{i}\right)$ 로 나타내면, 해 당 액정 층의 위상지연 $\Gamma_{i}$ 는

$$
\Gamma_{i}=\frac{2 \pi \Delta z}{\lambda}\left(\frac{n_{o} n_{e}}{\sqrt{n_{e}^{2} \cos ^{2} \theta\left(z_{i}\right)+n_{o}^{2} \sin ^{2} \theta\left(z_{i}\right)}}-n_{o}\right)
$$

이고, 회전 변환 행렬의 회전 각도는 $\phi\left(z_{i}\right)$ 이 된다. 결과적으
로 해당 액정 층의 Jones 행렬은 $\mathrm{W}\left(\Gamma_{i}, \phi\left(z_{i}\right)\right)=\mathbf{R}(-\phi) \mathbf{W}\left(\Gamma_{i}\right) \mathbf{R}$ $(\phi)$ 로 표현되고, 최종 액정 매질의 Jones 행렬 $\mathbf{M}_{L C}$ 은 총 $N$ 개 의 액정 방향자 층에 대해 다음과 같이 표현된다.

$$
\mathbf{M}_{L C}=\prod_{i=1}^{N} \mathbf{W}\left(\Gamma_{i}, \phi\left(z_{i}\right)\right)=\prod_{i=1}^{N} \mathbf{R}\left(-\phi\left(z_{i}\right)\right) \mathbf{W}\left(\Gamma_{i}\right) \mathbf{R}\left(\phi\left(z_{i}\right)\right)
$$

예를 들어, 두 장의 평행한 투명 기판이 $d$ 만큼 떨어져 있 고 액정의 모든 분자가 나란하게 정렬되어 있고 액정의 장축 이 기판에 평행한 경우를 생각해 보자. 이때 방향자 분포는 $\theta\left(z_{i}\right)=\pi / 2, \phi\left(z_{i}\right)=\phi_{0}$ (상수)로 표현된다. 이 경우, 식 (19)로 부터 $\Gamma_{i}=(2 \pi / \lambda)\left(n_{e}-n_{o}\right) d / N \equiv \Gamma / N$ 으로 위치에 무관한 상 수 값을 갖는다. 회전각도 $\phi_{0}$ 도 상수 이므로, $z_{i}$ 액정 층의 Jones 행렬은 $\mathbf{R}\left(-\phi_{0}\right) \mathbf{W}(\Gamma / N) \mathbf{R}\left(\phi_{0}\right)$ 으로 표현된다. 식 (20)을 이용해, 액정 층 전체의 Jones 행렬을 구하면,

$$
\mathbf{M}_{L C}=\prod_{i=1}^{N} \mathbf{R}\left(-\phi_{0}\right) \mathbf{W}\left(\frac{\Gamma}{N}\right) \mathbf{R}\left(\phi_{0}\right)=\mathbf{R}\left(-\phi_{0}\right) \mathbf{W}(\Gamma) \mathbf{R}\left(\phi_{0}\right)
$$

여기서, 회전 변환 행렬의 항등식 $\mathbf{R}(\phi) \mathbf{R}(-\phi)=\mathbf{I}$ 와 식 (17) 의 주대각 성분만 위상 지연으로 표현되는 행렬의 거듭제곱 특성 $[\mathbf{W}(\Gamma / N)]^{\mathrm{N}}=\mathbf{W}(N \Gamma / N)=\mathbf{W}(\Gamma)$ 를 이용했다. 만약, 입사 빛이 $x$-축으로 편광되어 있고, 검광자의 투과 축을 $y$-축으로 설정한 직교 편광 상태에서 빛의 투과도 $T$ 는

$$
\begin{aligned}
& E=\left(\begin{array}{ll}
0 & 1
\end{array}\right) \mathbf{R}\left(-\phi_{0}\right) \mathbf{W}(\Gamma) \mathbf{R}\left(\phi_{0}\right)\left(\begin{array}{l}
1 \\
0
\end{array}\right), \\
& T=E^{*} E=\sin ^{2}\left(2 \phi_{0}\right) \sin ^{2}\left(\frac{\pi \Delta n d}{\lambda}\right) .
\end{aligned}
$$

일반적으로 식 (22)는 전기장에 의한 복굴절(electrically controlled birefringence: $\mathrm{ECB})$ 액정 시편의 투과 특성을 나 타내며, $\phi_{0}=45^{\circ}, 135^{\circ}, 225^{\circ}, 315^{\circ}$ 에서 $\Delta n d / \lambda=1 / 2,3 / 2, \cdots$ 일 때 최대의 투과도를 갖는다. 또한, $\phi_{0}=0^{\circ}, 90^{\circ}, 180^{\circ}$, $270^{\circ}$ 에서는 위상 지연과 무관하게 항상 최소의 투과도를 보 인다. $\phi_{0}=0^{\circ}, 90^{\circ}, 180^{\circ}, 270^{\circ}$ 에서 최소의 투과도를 보이는 이유는 입사 빛의 편광이 고유벡터 방향과 일치하므로, 위상 지연이 발생하지 않고 입사 빛의 편광 상태가 변하지 않아 직교 편광자 상태에서 모든 빛이 차단되기 때문이다. 일반적 으로 전기장이 인가되어 액정 분자의 공간적인 변형이 일어 난 경우에는 수치 해석을 통해 방향자 분포를 구하고 식 (19) 와 식 (20)을 바탕으로 하여 복잡한 투과도를 계산할 수 있다.

\section{V. 결 론}

본 총설에서는 액정의 구조적 질서와 이에 따른 다양한 액 정 상에 대해 기술했으며, 액정의 비등방적 물성, 외부 전기 
장(자기장)과의 상호작용 및 표면과의 상호작용에 대해 이론 적으로 설명했다. 또한, 액정은 연속체 이론에서의 탄성적 변형 에너지, 액정과 전기장 간의 상호작용(유전 이방성 혹 은 자발분극)에 의한 전기 에너지, 표면과 액정 간의 상호작 용인 표면 고정 에너지의 총합이 최소화될 때 평형 상태에 도달함을 보였다. 액정의 비등방성을 바탕으로 전기장에 의 한 액정 분자의 재정렬 현상을 이해했으며, 전자기파인 빛에 대한 비등방성을 편광 광학 측면에서 해석했다. 마지막으로, 간단한 액정 광학소자의 투과도를 $2 \times 2$ Jones 행렬법을 이용 하여 해석적으로 구하고 의미를 설명했다. 본 총설이 뒤에 게재될 액정 디스플레이 소자의 동작원리인 액정모드의 물 리적 광학적 특성을 이해하는 기초를 제공할 것이다.

\section{감사의 글}

이 논문은 삼성 디스플레이의 지원으로 수행되었습니다. 또한, 이 논문은 한국연구재단(No 2011-0016968)의 지원으 로 수행되었습니다.

\section{References}

1. P. G. de Gennes and J. Prost, The Physics of Liquid Crystals, 2nd ed. (Oxford University Press, New York, USA, 1993).

2. S.-D. Lee, "A numerical investigation of nematic ordering based on a simple hard-rod model," J. Chem. Phys. 87, 4972-4974 (1987).

3. S.-D. Lee, "The Onsager-type theory for nematic ordering of finite-length hard ellipsoids," J. Chem. Phys. 89, 7036-7037 (1988).

4. T. S. Sluckin, D. A. Dunmur, and H. Stegemeyer, Crystals That Flow: Classic Papers from The History of Liquid Crystals (Tayor and Francis, London, UK, 2004).

5. S. Elston and R. Sambles, The Optics of Thermotropic Liquid Crystals (Tayor and Francis, Padstow, 1998).
6. K.-S. Bae, Y.-J. Jang, Y.-K. Moon, S.-G. Kang, U. Cha, C.-J. Yu, J. E. Jang, J. E. Jung, and J.-H. Kim, "Multicolor cholesteric liquid crystal display in a single-layered configuration using a multi-pitch stabilizations," Jpn. J. Appl. Phys. 49, 084103 (2010).

7. P. R. Gerber, "Electro-optical effects of a small-pitch blue-phase system," Mol. Cryst. Liq. Cryst. 116, 197-206 (1985).

8. H. Kikuchi, M. Yokota, Y. Hisakado, H. Yang, and T. Kajiyawa, "Polymer-stabilized liquid crystal blue phases," Nat. Mater. 1, 64-68 (2002).

9. F. Castles, F. V. Day, S. M. Morris, D.-H. Ko, D. J. Gardiner, M. M. Qasim, S. Nosheen, P. J. W. Hands, S. S. Choi, R. H. Friend, and H. J. Coles, "Blue-phase templated fabrication of three-dimensional nanostructures for photonic applications," Nat. Mater. 11, 599-603 (2012).

10. S.-T. Hur, B. R. Lee, M.-J. Gim, K.-W. Park, M. H. Song, and S.-W. Choi, "Liquid-crystalline blue phase laser with widely tunable wavelength," Adv. Mater. 25, 3002-3006 (2013).

11. A. Rapini and M. J. Papoular, "Distortion d'une lamelle nematique sous cham magnetique conditions d'ancrage aux parois," J. Phys. (Paris) Colloq. 30, C4-54-C4-56 (1969).

12. R. B. Meyer, L. Leibert, L. Strzelecki, and P. Keller, "Ferroelectric liquid crystals," J. Phys. (Paris) Lett. 36, L-69-71 (1975).

13. R. B. Meyer, "Piezoelectric effects in liquid crystals," Phys. Rev. Lett. 22, 918-921 (1969).

14. G. Hegde and L. Komitov, "Periodic anchoring condition for alignment of a short pitch cholesteric liquid crystal in uniform lying helix texture," Appl. Phys. Lett. 96, 113503 (2010).

15. P. Yeh, Optical Waves in Layered Media, 2nd ed. (John Wiley \& Sons, Chichester, UK, 2005).

16. D.-K. Yang and S.-T. Wu, Fundamentals of Liquid Crystal Devices (John Wiley \& Sons, Chichester, UK, 2006). 